\title{
De la permisibilidad a la restricción. Un análisis de la incidencia de los condicionantes sistémicos sobre la política exterior del kirchnerismo (2003-2015)
}

\author{
Actis, Esteban** \\ Busso, Anabella ${ }^{* * *}$ \\ Calderón, Emilse ${ }^{* * *}$ \\ Zelicovich, Julieta ${ }^{* * * *}$
}

\section{Resumen:}

Existe un consenso amplio sobre la importancia que los condicionantes domésticos tuvieron en el diseño de la política exterior durante los gobiernos de Néstor y Cristina Kirchner. En consonancia con ese diagnóstico los condicionantes sistémicos han tendido a ser dejados de lado en los estudios referidos a la política exterior argentina durante esa etapa. Por ello, en este trabajo, pretendemos cubrir parte de esa laguna. Consecuentemente argumentamos, a modo de hipótesis, que los condicionantes sistémicos no fueron constantes en los doce años de gestión kirchnerista, sino que mudaron desde un perfil permisivo a uno más restrictivo en el segundo mandato de Cristina Fernández. Esta dinámica tuvo impacto sobre múltiples dimensiones de la Política Exterior, pero fue más evidente en el ámbito económico.

Palabras claves: política exterior; condicionantes sistémicos; Kirchnerismo; permisibilidad; restricción

\section{From permissibility to restriction. An analysis of the incidence of systemic constraints on Kirchner's foreign policy (2003-2015)}

\begin{abstract}
:
There is a broad consensus on the importance that the domestic constraints have had on the design of foreign policy during the governments of Néstor and Cristina Kirchner. In line with this diagnosis, systemic constraints have tended to be neglected in the studies related to the argentinean foreign policy during this period. Therefore, in this work, we intend to fill part of that gap. For this reason, by way of hypothesis, we argue that the systemic factors were not constant in the twelve years of Kirchner's administration, but that they changed from a permissive profile to a more restrictive one in the second term of Cristina Fernández. This dynamic had an impact on multiple dimensions of foreign policy, but was more evident in the economic sphere.
\end{abstract}

Key words: foreign policy; systemic constraints; Kirchnerism; permissibility; restriction

Trabajo enviado: 04/04/2017 Trabajo aceptado: 10/06/2017

\footnotetext{
* Este trabajo se inscribe en el marco del Proyecto de Investigación Plurianual: "La Política Exterior Argentina inmersa en la crisis económica internacional" (CONICET). El trabajo es en co-autoría y el orden en el que se mencionan los autores es estrictamente alfabético.

** Esteban Actis, Doctor en Relaciones Internacionales, Universidad Nacional de Rosario, Consejo Nacional de Investigaciones Científicas y Técnicas. Correo electrónico: e.actis@conicet.gov.ar

*** Anabella Busso, Master en Ciencias Sociales, Universidad Nacional de Rosario, Consejo Nacional de Investigaciones Científicas y Técnicas. Correo electrónico: anabella.busso@ @cpolit.unr.edu.ar

***** Emilse Calderón, Doctora en Relaciones Internacionales, Universidad Nacional de Rosario, Consejo Nacional de Investigaciones Científicas y Técnicas. Correo electrónico: emilsecalderon@ hotmail.com

****** Julieta Zelicovich, Doctora en Relaciones Internacionales, Universidad Nacional de Rosario, Consejo Nacional de Investigaciones Científicas y Técnicas. Correo electrónico: julieta.zelicovich@fcpolit.unr.edu.ar
} 


\section{Introducción}

En su carácter de paradigma teórico predominante la Escuela Realista clásica (MORGENTHAU, 1948) logró imponer, durante décadas, el supuesto de que los factores explicativos de las políticas exteriores de los estados se encontraban únicamente en el contexto internacional, concibiendo al diseño de esta política pública como una respuesta a las amenazas y oportunidades del escenario externo.

En esta visión, el Estado "es un actor racional y unificado que adopta una política exterior (PE) como reflejo de los riesgos y ocasiones que le presenta el sistema internacional global o regional- con el fin de maximizar sus intereses" (LASAGNA, 1996: 45). Consecuentemente, estos enfoques asumen que la PE se configura en un proceso relativamente aislado de la sociedad en la que ocurre donde los debates internos no juegan un rol central. Posteriormente, según Soares de Lima (1994), los enfoques del modelo político-social se distanciaron del anterior en tanto entendieron que las preferencias externas son siempre endógenamente determinadas y no son fijas. Estos hacen énfasis en el proceso de formación de políticas y no en los atributos del Estado o su ubicación relativa. En el ámbito disciplinar de las Relaciones Internacionales estas visiones se vinculan con el modelo de política burocrática de Graham Allison (1975), pero poseen antecedentes en la sociología política clásica sobre el análisis de políticas gubernamentales. Esta línea conceptual, que incluye tanto a visiones pluralistas como marxistas, considera que la policy es consecuencia de las actividades de los grupos de interés y de las fuerzas sociales y, aplicado al estudio de la PE, entiende al contexto externo como fijo (SOARES DE LIMA, 1994). Finalmente, los trabajos de Rosenau (1967) y más específicamente los de Putnam (1988) dan lugar al modelo interactivo el cual se presenta como superador de los dos anteriores. Esta postura teórica reserva, al igual que lo hace el modelo realista clásico, el ámbito de la PE a la acción de los representantes del Estado, pero incluye el análisis de los determinantes domésticos de la acción externa. Al privilegiar la interacción entre el contexto externo y los determinantes internos en este enfoque no sólo las preferencias externas dejan de ser fijas, sino también el contexto internacional (SOARES DE LIMA, 1994).

Desde nuestra perspectiva adherimos a los supuestos del modelo interactivo y, además, acordamos con Russell (1991), que el debate sobre la prevalencia de un tipo u otro de condicionantes sobre la PE no es de orden filosófico, sino empírico. Consecuentemente, su capacidad explicativa sobre la PE depende de los distintos momentos históricos y de las cuestiones analizadas.

En el caso específico de los gobiernos kirchneristas existe un consenso amplio referido a que los condicionantes domésticos fueron los que primaron en la definición del diseño de la PE. Tal realidad ha sido puesta en evidencia en numerosos estudios tales como Busso (2010 y 2016); Miguez (2016) y Russell y Tokatlian (2015). En consonancia con esos diagnósticos los condicionantes sistémicos han tendido a ser dejados de lado en los estudios referidos a la PE durante esa etapa. Por ello en este trabajo buscamos poner el foco en dicha laguna.

Es sabido que los condicionantes sistémicos son de origen externo y pueden ser de orden político, económico, estratégico, cultural, social, entre otros. Si bien el concepto "condicionante" suele tener una connotación negativa (sus equivalentes son supeditar, subordinar, limitar, restringir, coartar), consideramos necesario destacar que en caso de ser utilizado como sinónimo de influencia o, desde una perspectiva metodológica, como una variable, dicho concepto debe ser entendido en un sentido más amplio en tanto la condicionalidad generada puede ser permisiva o restrictiva y variar en su intensidad.

Las nociones de permisibilidad y restricción hacen alusión a las características particulares que adquiere el orden internacional en sus diversas dimensiones en un contexto determinado. Dichas características pueden mostrar la existencia o ausencia de condicionantes externos que limiten o potencien las opciones nacionales en la arena internacional. Retomando la tradicional conceptualización de Helio Jaguaribe (1969), la permisibilidad/restricción internacional alude a las condiciones de posibilidad para un Estado o un conjunto de Estados de emprender una estrategia autonomizante tomando en cuenta el estado de situación - 
flexibilidad/rigidez- o el grado de condicionamientos específicos del sistema internacional en un momento histórico determinado.

En relación con estas referencias, e independientemente de la valoración ideológica que se realice, a lo largo de este trabajo entendemos que tanto el discurso como las principales acciones de PE a lo largo de los gobiernos kirchneristas se diseñaron en función de lograr una acción externa autonómica y ligada a un modelo económico neo-desarrollista. Es, entonces, desde esta afirmación que analizaremos el rol de los impactos externos sobre la búsqueda y concreción de dicho modelo de PE.

A partir de estas consideraciones sostenemos a modo de hipótesis que los condicionantes externos (variables sistémicas) no fueron constantes en los doce años de gestión kirchnerista, sino que mudaron desde un perfil permisivo durante los primeros años, a uno más restrictivo en el segundo mandato de Cristina Fernández. Esta dinámica tuvo impacto sobre múltiples dimensiones de la PE, pero fue más evidente en el ámbito económico.

Por una cuestión de espacio no podemos desarrollar taxativamente el conjunto de condicionantes externos, pero a los efectos de sustentar empíricamente nuestra afirmación presentamos en primer lugar un breve recorrido general sobre el cambio en el perfil y la intensidad de los condicionantes externos y su impacto sobre distintos aspectos de la PE; en segundo lugar nos concentraremos de manera más específica en la dimensión económica abordando la globalización financiera y las variaciones en el comercio internacional; en tercer lugar echamos una mirada a la dimensión estratégico-militar para cerrar con algunas conclusiones.

\section{Una mirada general sobre la incidencia de los condicionantes sistémicos}

Pensar la interacción entre la Política Exterior Argentina (PEA) y los condicionantes externos en el escenario de 2003 -cuando Néstor Kirchner llegó a la Casa Rosada- nos trae a la memoria la persistencia de numerosos problemas generados a partir de la crisis desatada en 2001, cuya nota distintiva en términos internacionales era el default a lo que se sumaba un contexto global interpelado por la guerra contra el terrorismo internacional. Por ello es tentador pensar que esa fue, entonces, la etapa donde la condicionalidad externa generó las mayores restricciones para la gestión externa de nuestro país. Sin embargo, como sostuvimos en nuestra hipótesis, una revisión más detallada de los hechos nos permite afirmar que ese camino fue a la inversa transitando de una mayor permisividad externa a un escenario más restrictivo. Dicho en otras palabras, una mirada a los aspectos sustantivos nos permite argumentar que los constreñimientos internacionales fueron más severos en épocas de Cristina que durante la gestión de Néstor Kirchner y, de esta forma, limitaron las opciones de la política externa y económica internacional a medida que transcurrían la gestión kirchnerista.

Si reorientamos la mirada hacia la dimensión política, el gobierno de Néstor Kirchner se superpuso con las discusiones preliminares sobre la conformación del orden internacional en el siglo XXI y las respectivas consecuencias en la distribución del poder mundial. Para 2003 el orden internacional estaba enmarcado por la guerra contra el terrorismo internacional liderada por Estados Unidos con posterioridad a los ataques de septiembre de 2001. Esto implicó un proceso de militarización de la acción externa de Washington; la implementación de la doctrina Bush (acción preventiva); un predominio de las visiones políticas neoconservadoras y economías liberales y una abundante literatura que señala la llegada de una nueva paxamericana basada en el establecimiento de la primacía a través del uso de la fuerza. Si bien estas tendencias se tradujeron en una cierta desatención de Washington hacia Sudamérica, Argentina recibió el apoyo de la administración de George W. Bush en el proceso de renegociación de deuda soberana que llevó adelante Kirchner junto al ministro de economía, Roberto Lavagna. ${ }^{1}$

\footnotetext{
${ }^{1}$ Las diferencias que la administración de George W. Bush y su primer Secretario del Tesoro, Paul O Neill, mantuvieron con Wall Street generaron un ámbito favorable para que el gobierno de Estados Unidos apoye a la Argentina en su proceso de renegociación de deuda (BUSSO y PIGNATTA, 2006).
} 
Las tensiones expresas con el gobierno estadounidense se presentaron a partir de 2005 debido al rechazo al ALCA que Argentina compartió junto a los otros miembros del Mercosur en la Cumbre de las Américas en Mar del Plata.

La situación a lo largo de los gobiernos de Cristina fue diferente porque las transformaciones internacionales se dieron de manera más acelerada y generaron mayor incertidumbre. En estos años Estados Unidos y Europa transitaron por la crisis económica iniciada en 2008; se discutió con mayor contundencia el rol de las potencias emergentes especialmente los BRIC en forma conjunta y China como actor individual-y se consolidaron las tendencias que indicaban el traslado del eje económico mundial a la región del Asia Pacífico. Posteriormente, la situación internacional sumó nuevos matices caracterizados por disputas con reminiscencia de Guerra Fría donde Estados Unidos y Europa sancionaron a la Federación Rusia por la crisis en Ucrania y se incrementó la preocupación de los poderes occidentales ante el aumento de los atributos económicos, políticos y militares de China. Por otra parte, como sostiene Busso (2014) las relaciones con Washington durante las gestiones de Cristina Kirchner estuvieron caracterizadas por una dinámica permanente de crisis-intento de recomposición ${ }^{2}$ hasta llegar a un estado de parálisis a partir del momento en que el gobierno de Obama dejó de apoyar a la Argentina ante la decisión de la Corte Suprema de Estados Unidos de no tomar el caso argentino para analizar la decisión del juez Griesa.

En estrecha vinculación con este último tema también sobrevino una situación internacional sustancialmente diferente entre un gobierno y otro. Entre 2003 y marzo de 2005 la PE de Néstor Kirchner estuvo claramente formateada por el proceso de renegociación de deuda soberana para salir del default. Si bien esta etapa fue muy intensa y compleja finalizó exitosamente. En el marco de una agenda externa más diversificada la cuestión de la deuda ocupó nuevamente un lugar relevante en 2010, cuando en el gobierno de Cristina se concretó la segunda renegociación de deuda. Sin embargo, en su último mandato otra vez el panorama volvió a ser más complejo para ella que para su antecesor. La decisión del juez Griesa de dar lugar a las demandas de los llamados fondos buitres no sólo puso en tensión los vínculos con Estados Unidos y parte del sector financiero internacional, sino que obligó a la Argentina a desarrollar una gran actividad internacional en búsqueda de apoyos y afectó fuertemente la actividad política al interior de las fronteras desatando nuevamente fuertes críticas al gobierno desde los medios hegemónicos y los partidos de oposición. Si bien el gobierno impuso su lógica de negociación y no concretó los pagos establecidos por Griesa, la situación generó distintas instancias de turbulencia política cuando en febrero de 2012 se conoció la decisión del juez

Entendía que los inversionistas ya habían sido muy protegidos por las políticas de salvataje y ahora debían someterse a los riesgos de perder en un proceso de renegociación. Roberto Lavagna (2005) afirma que tanto en la crisis del Tequila como en las sucedidas en el Sudeste Asiático, Rusia y Brasil, el FMI y el Tesoro norteamericano impulsaron un rol considerablemente activo del organismo como prestamista de última instancia. Sin embargo, a partir de 2000 se comenzó a considerar que esta estrategia de minimización de riesgos había acarreado un problema: la disminución de los incentivos de los inversores para evaluar cuidadosamente los riesgos a asumir (que se evidenciaban en el alto nivel de las tasas de interés a la cual se invertían los fondos). La garantía implícita de un rescate impedía, por un lado, que los inversores sufrieran las consecuencias de una mala evaluación y, por otro lado, resultaba en una "incorrecta" asignación de los recursos a nivel internacional. La posición asumida por parte del gobierno de Estados Unidos a partir de 2000 se basó en estas consideraciones. Para Washington el esquema de salvatajes había generado incentivos perversos y era necesaria una vuelta a las leyes de mercado.

2 Cuando hacemos referencia al patrón crisis-intento de recomposición sin llegar a una ruptura pretendemos señalar que, "en el marco de las diferencias existentes entre Argentina y EE.UU bajo los gobiernos de Cristina Fernández, los vínculos bilaterales tuvieron la siguiente dinámica: a- se producían situaciones de tensión (crisis) ligadas a diferencias de índole política, económica y estratégico militar; bcada una de ellas fue seguida por contactos y/o negociaciones a nivel ministerial o presidencial que pretendían acercar a las partes (intento de recomposición), sin que ello implicase por parte de Argentina optar nuevamente por políticas de alineamiento; c- esta dinámica no conducía a la ruptura porque ambas partes siempre eligieron restablecer, al menos, un nivel de cordialidad mínima y, además, porque en el ámbito multilateral nuestro país no optó por un perfil de voto anti-estadounidense.” (BUSSO, 2014: 51). 
Griesa; en octubre del mismo año cuando la Corte del distrito de Nueva York confirmó el fallo y en 2014 cuando la Corte Suprema de Estados Unidos no tomó el caso.

Otra diferencia que aportan los condicionantes externos, en este caso de intensidad, entre los períodos de gobierno se vincula con el rol de China en el mundo y sus relaciones con la región y Argentina. En primer lugar hay que subrayar que a partir de 2001 con el ingreso de China a la OMC este país comenzó un tránsito ascendente a nivel global, superando la influencia regional que había alcanzado. Si bien Néstor Kirchner le dio una gran prioridad a la dimensión comercial en el marco de la PEA, organizó una misión oficial acompañado por empresarios a China y le otorgó en 2004 el reconocimiento de economía de mercado tal como lo solicitaba Beijín; desde mediados de la primera década del siglo XXI hasta el presente las inversiones y el comercio tanto con la región ${ }^{3}$ en su conjunto como con Argentina ${ }^{4}$ en particular, han aumentado de manera muy significativa. Consecuentemente, la relación con China se convirtió en un vínculo de mayor peso en épocas de Cristina que en épocas de Néstor Kirchner.

El contexto regional también fue muy diferente entre la primera y la segunda década del siglo XXI. La dinámica política y económica positiva que se dio en América del Sur en la primera década del siglo XXI, enfrentó desde 2011 y de manera creciente una parálisis. El debilitamiento del llamado "giro a la izquierda" conllevó que las propuestas de concertación política hayan sido más efectivas durante la gestión de Kirchner y el primer gobierno de Cristina, que durante su segundo mandato. En este mismo contexto la voluntad de los gobiernos para aplicar modelos económicos neo-desarrollistas comenzó a ser menos preponderante en el escenario regional. Las situaciones domésticas impactaron sobre el diseño de la PE y reaparecieron con mayor regularidad las demandas por acuerdos de libre comercio y las propuestas para reorientar los procesos de integración regional en esa dirección lo que, de hecho, significaba abandonar los conceptos de regionalismo pos-neoliberal y pos-hegemónico.

Desde una perspectiva general la economía internacional durante la gestión de Kirchner coincidió con una etapa de relativa estabilidad global, mientras que a Cristina le correspondió atender las secuelas de la crisis económico-financiera desatada en los estados centrales en 2008. Esta fue sólo equiparable a la crisis del '30 y generó consecuencias globales, entre las que se destacan: a- una contracción del comercio internacional por caída de la demanda que afectó la balanza comercial argentina situación que se complicó aún más a partir de 2011 con la crisis energética y la necesidad de incrementar las importaciones; b- las discusiones multilaterales en torno a los mecanismos para reglar las actividades financieras internacionales, marco en el que Argentina manifestó su postura favorable a la regulación; y c- el debate sobre

\footnotetext{
${ }^{3}$ La IED de China en América Latina y el Caribe en los casi 20 años que transcurrieron entre 1990 y 2009 alcanzó un total de 7.340 millones de dólares. Sin embargo estas cifras se expandieron significativamente. A modo de referencia sólo en 2010 la IED de origen chino alcanzó los 13.712 millones de dólares; en 2011 llegó a los 10.175 millones; en 2012 a los 9.206 millones y en 2013 a los 9.624. CEPAL (2015). Por otra parte, durante la primera década del siglo XXI el intercambio comercial entre la región y China ha sido muy dinámico. De acuerdo a la CEPAL (2012) las exportaciones en porcentajes pasaron de 26,8 en el período 2000/2005 al 31,6 en la etapa 2005/2011, mientras que las importaciones lo hicieron de 37,6 a 28,2 .

${ }^{4}$ La IED de origen chino en Argentina entre 1990-2009 fue de 143 millones de dólares. En el año 2010 ascendió a 3.100 millones; en 2011 fue de 2.450; en 2012 de 600 y en el 2013 de 120 millones (CEPAL, 2015). Por otra parte China es el segundo socio Comercial de Argentina tanto a nivel de importaciones como exportaciones. Entre 1994 y 2014 el comercio Argentina-China medido en dólares corrientes se multiplicó por 16, lo que implicó una tasa de crecimiento promedio anual de $15,1 \%$, muy superior a la tasa evidenciada para el comercio exterior argentino en su conjunto, que fue de 6,7\%. Estos resultados derivaron en que la incidencia de China en el intercambio exterior de Argentina pasara de un 2,5\% en 1994 al 11,5\% actual. En lo que respecta a exportaciones, la participación pasó de 1,40 a 7\%, mientras que en lo que refiere a las importaciones la incidencia se elevó de 3,40 a 16,50\%. (2015). El peso de China en la balanza comercial argentina tocó su máximo histórico en 2014, Diario Cronista.com, $1^{\circ}$ de febrero de 2015, Buenos Aires [en línea]. Disponible en: http://www.cronista.com/economiapolitica/Elpeso-de-China-en-la-balanza-comercial-argentina-toco-un-maximo-historico-en-2014-201502010009.html
} 
las políticas económicas para enfrentar la crisis enmarcado entre las opciones de ajuste o de políticas activas/expansivas, ante el cual el gobierno de Cristina optó por la segunda alternativa.

En el ámbito económico-comercial, Néstor Kirchner transitó un período de ascenso lento pero persistente de precios de los commodities, especialmente de la soja. Esto fue sumamente favorable para el país en tanto articulado con una política de tipo de cambio competitivo favoreció una balanza comercial positiva y, simultáneamente, el ingresos de divisas a pesar de la restricciones financieras por el default y las negociaciones para salir del mismo. Si bien, los precios de la soja alcanzaron su máximo nivel durante la primera gestión de Cristina (2008) a inicios de su segundo mandato (2012), el panorama cambió sustancialmente a partir de ese momento afectando el ingreso de dólares por exportaciones ${ }^{5}$.

Esta breve descripción ejemplifica, desde una perspectiva general, cómo los condicionantes externos fueron transitando desde la permisividad a la restricción. A continuación analizamos más detalladamente los condicionantes externos de orden económico los cuales, tal cual lo adelantamos, son los que mayor impacto generaron sobre la PEA facilitando posturas más autónomas y relaciones más diversificadas en la etapa permisiva características que, claramente, se vieron acotadas con la consolidación de un escenario internacional más restrictivo.

\section{La globalización financiera y su condicionamiento sobre la PEA}

Desde finales de los años setenta del pasado siglo hasta la actualidad, la irrupción de la globalización financiera ${ }^{6}$ se transformó en un condicionante para el desarrollo económico y la inserción internacional de todas las naciones, principalmente aquellas periféricas ${ }^{7}$. A diferencia de otros condicionantes externos de carácter momentáneo y coyuntural, la globalización financiera representa un constreñimiento estructural del capitalismo actual (BRESSER PEREIRA, 2010)

A partir de entonces, la PEA se vio cada vez más afectada por este condicionante externo. Como ejemplos podemos mencionar el intento del gobierno de Raúl Alfonsín de crear un "club de deudores" para negociar con la banca privada internacional (CAPUTO, 2015), la

\footnotetext{
${ }^{5}$ Conforme a los datos de UNCTAD STATS, después de haber alcanzado un pico en el año 2011, el índice de los precios de los commodities agrícolas enfrentó una tendencia a la baja, pasando de medir 289 puntos en $2011(2000=100)$ a 161 puntos en 2015.

${ }^{6}$ Desde la década del setenta del pasado siglo, el modelo de acumulación capitalista experimentó una nueva ola de su fase de integración, fenómeno conocido popularmente como globalización (FERRER, 1996). Si hasta los años setenta existían atomizados sistemas financieros primordialmente de carácter nacional cuya principal función era intermediar y canalizar recursos de ahorristas a los agentes económicos (estados y empresas) con necesidad de financiamiento, el fin del sistema de Bretton Woods inició una era de relativa autonomía del sector financiero (ahora de carácter global dado el fin de las restricciones nacionales a la hora de invertir en cartera) desacoplado de la globalización productiva (EATWELL y TAYLOR, 2005). La globalización financiera es un proceso histórico en dos dimensiones. En una, la globalización está representada por el creciente volumen de transacciones financieras a través de las fronteras. En la otra, por la secuencia de reformas institucionales y legales que se fueron realizando para liberalizar y desregular los movimientos internacionales de capital y los sistemas financieros nacionales (FRENKEL, 2003). Este fenómeno distorsionó por completo el objeto de las finanzas: sumar ahorros de una cantidad de agente y transformarlo en inversiones y consumo a largo plazo. En lugar de ello, la financierización implicó un enorme aumento de la riqueza financiera ficticia porque no guardó relación con la producción. En Estados Unidos la riqueza financiera aumentó desde 1980 alrededor de 4 veces más que el PBI (BRESSER PEREIRA, 2010).

${ }^{7}$ La principal amenaza para los países en desarrollo ha estado dada por la condición asimétrica en relación a las reglas de juego de la globalización financiera. Mientras que unos son simplemente seguidores de reglas (rules-taker), los otros, los Estados y las empresas del denominado mundo desarrollado, son formuladores (rules-makers). Esta diferencia estructural no significa que existan actores que no estén propensos a sufrir la vulnerabilidad propia de la globalización, tal como lo señaló oportunamente Susan Strange - y que la crisis del 2008 demostró con creces-, pero es necesario afirmar que los márgenes de maniobra no son homogéneos.
} 
profundización de la dependencia con los organismos multilaterales de crédito (FMI) después del "efecto tequila" en 1995 (BUSSO, et al, 2016), los esfuerzos del gobierno de Fernando de la Rúa para que la Argentina fuese sumada a la gobernanza global a partir de la creación del G-20 en 1999 (PETRELLA, 2011) y las dificultades del gobierno interino de Eduardo Duhalde de lograr el apoyo de los Estados Unidos y del FMI para salir de la crisis del default (MIRANDA, 2014).

En ese marco, la PE de los gobiernos kirchneristas no han sido la excepción, por el contrario, durante los doce años de gestión los impactos de la globalización financiera sobre la agenda externa fueron significativos. A los fines del trabajo identificamos tres etapas particulares (2003-2005; 2008-2010 y 2014-2015) en las cuales se vislumbra con claridad cómo la dinámica de la globalización financiera impactó en la agenda externa de los gobiernos kirchneristas.

Es posible identificar una primera etapa en el recorte temporal del trabajo vinculado a los dos primeros años del gobierno de Néstor Kirchner (2003-2005) en donde la PEA quedó prácticamente reducida al objetivo de salir del default. En aquel momento, las principales relaciones bilaterales (EEUU, Europa y Brasil), las relaciones con los organismos internacionales y el vínculo con distintos actores del mercado transnacional estuvieron condicionados por los intentos de dejar atrás el aislamiento internacional producto de la cesación de pagos (MIRANDA, 2014; NEMIÑA, 2013, CREUS, 2015). En ese marco el presidente Kirchner decidió mantener en funciones a Roberto Lavagna, quien ya se desempeñaba como Ministro de Economía en el gobierno de Duhalde, y había iniciado el proceso de negociación para reestructurar la deuda soberana más importante de la historia hasta ese momento. La operatoria del canje se concretó en marzo de 2005 y, como lo adelantamos en la primera parte de este trabajo, contó con el apoyo de los Estados Unidos. El nivel de aceptación final alcanzó el 76,15\% del monto de deuda en situación irregular y fue considerado un proceso de negociación exitoso (FERNÁNDEZ ALONSO, 2006). Esta tarea se enlazó con la decisión del gobierno argentino de cancelar la totalidad de la deuda con el FMI en diciembre de 2005, la cual ascendía a 9810 millones de dólares y fue cubierta con reservas del Banco Central. De esta manera Kirchner lograba uno de sus objetivos centrales consistente en limitar la tutela del FMI, la cual era considerada un condicionante externo relevante.

Sin embargo, como evidenciaremos, durante la segunda y tercera etapa se produce una particularidad caracterizada por una lógica invertida en relación a la configuración del sistema financiero internacional. En términos operativos, en un momento sistémico altamente restrictivo (2008-2010) la Argentina logró mantener (como en la primera etapa) una relativa autonomía que le permitió disponer de mayores márgenes de maniobra en su PE. Por su parte, en una coyuntura global permisiva de la globalización financiera para los países emergentes (2014-2015) la Argentina se vio condicionada producto del poderío de un actor específico del sistema financiero (los denominados fondos buitres) lo que condujo a una limitación y reorientación de algunas líneas de la PE.

En relación al segundo momento señalado ${ }^{8}$ cabe indicar que la crisis en los mercados mundiales alteró la estrategia del gobierno argentino de continuar con el proceso de

\footnotetext{
${ }^{8}$ Desde 2008 el mundo experimentó el inicio (y los posteriores coletazos) de una crisis financiera internacional con epicentro en los Estados Unidos comparable únicamente con el crack bursátil de 1929. En términos conceptuales, el estallido de la burbuja subprime de Wall Street se transformó en un elemento sistémico altamente restrictivo con afectaciones en el canal financiero y en la economía real de las distintas naciones. Sin embargo, a diferencia de otros países en desarrollo, la Argentina logró un relativo desacople de la crisis debido a baja exposición frente a la globalización financiera luego de haber regularizado, como ya lo indicamos, en 2005 una parte significativa de la deuda en default y la que mantenía con el FMI. Compartimos la afirmación de Susana Nudelsman (2013) que países de América Latina como Argentina, Brasil y Chile arribaron al episodio de crisis global en condiciones más robustas que en las anteriores. Niveles bajos de inflación, superávit en las cuentas externas y fiscales, sistemas bancarios saludables, una existencia importante de reservas internacionales y sistemas cambiarios más flexibles confirieron a la región un alto grado de fortaleza. Esta situación permitió a las economías de la
} 
desendeudamiento y normalización de los temas pendientes del default pero acentuó la convicción de profundizar la prescindencia de la globalización financiera y apostar a los beneficios de la globalización comercial ${ }^{9}$. La decisión política obedecía, dada la reciente experiencia traumática, a reducir los efectos adversos de una inserción en el sistema financiero vinculados, como sostiene French Davis (2016) a la inversión especulativa la cual por su carácter fuertemente pro-cíclico no hace más que agudizar los desequilibrios, aumentar los niveles de incertidumbre y volatilidad del mercado.

En lo relativo con la estrategia de desendeudamiento, a inicios de septiembre de 2008 la Presidenta Cristina Kirchner había anunciado el pago a los países acreedores que conforman el denominado Club por un monto superior de 6000 millones de dólares ${ }^{10}$. No obstante, cuando en noviembre estalló la crisis en los Estados Unidos, la profunda inestabilidad en el sistema financiero postergó la decisión de cancelar aquella deuda quedando sin efecto los contactos realizados con los gobiernos de Francia, Alemania, Japón entre otros. Lo mismo ocurrió con la planificación de la reapertura de un canje (implicaba contactos con la burocracia de los Estados Unidos y con los bancos internacionales) para aquellos tenedores de deuda que no ingresaron en 2005, propuesta que se formalizó en $2010^{11}$ cuando lo peor de la crisis había pasado. El proceso de crecimiento con ahorro interno posibilitó amortiguar los impactos del contexto restrictivo en dicha dimensión de la globalización y evitar así otro episodio de vulnerabilidad financiera. Asimismo, amplió los márgenes de maniobra de la Argentina en el escenario internacional para desplegar la "lógica de la autonomía" (RUSSELL y TOKATLIAN, 2013) como fundamento de la política exterior.

Al final del segundo mandato de Cristina Kirchner la Argentina vio condicionada su política exterior producto de una dinámica, inesperada para las autoridades nacionales, de la globalización financiera como fue la receptividad de los denominados "fondos buitres ${ }^{12}$ " en todas las instancias de la justicia norteamericana.

Durante cierto tiempo el accionar de los "fondos buitres" se concentró en constantes intentos por embargar activos del Estado argentino, pero esta estrategia no brindó el rédito esperado. De este modo, ante el fracaso y la falta de resultados concretos, en octubre de 2010 NML Capital Ltd. modificó su estrategia y reorientó el argumento de su demanda legal, planteando la violación por parte de Argentina de la cláusula pari passu la cual refiere al trato igualitario de todos los bonistas acreedores. El 23 de febrero de 2012 el Juez Griesa emitió una orden mediante la cual le solicitó a la Argentina pagar en su totalidad a los bonistas

región responder al efecto global con políticas anticíclicas, lo que difiere de la respuesta de estas economías en episodios anteriores de efectos externos.

9 Entre el 2003 y 2007 la Argentina logró un crecimiento económico con "ahorro interno" es decir con dólares genuinos provenientes del canal comercial. El alto precio de las materias primas (principalmente la soja) y un tipo de cambio competitivo fueron funcionales a mejorar la oferta y diversificar la exportadora.

${ }^{10}$ Los enigmas del pago al Club de París, Página 12, 5 de septiembre de 2008, Buenos Aires. Disponible en: https://www.pagina12.com.ar/diario/economia/2-111035-2008-09-05.html

${ }^{11}$ El proceso de restructuración se realizó durante el período abril-agosto de 2010. El monto elegible para este canje fue de U\$S18.300 millones (incluía intereses devengados e impagos al 31-12-01) y el porcentaje de aceptación alcanzó el 67\%, involucrando el rescate de U\$S12.210 millones de monto elegible. Teniendo en cuenta los montos ingresados en este canje, junto con lo ingresado en el canje 2005 se llegó a regularizar más del $91 \%$ de la deuda elegible en el canje 2005.

${ }^{12}$ Luego del canje de deuda de 2010, solamente un 7\% de los acreedores seguían conservando bonos argentinos en default. Entre ese pequeño grupo de acreedores se encontraban los "holdouts" o "fondos buitres" dedicados a adquirir títulos de deuda de países con dificultades a precios sumamente bajos producto obviamente del riesgo de impago que entrañan-, para luego una vez producido el default, judicializar la disputa y reclamar por el $100 \%$ del valor del título en cuestión. Esto último es lo que los diferencia de otros fondos de inversión de riesgo que también se dedican a la compra de títulos de deuda con alto riesgo de default o incluso ya en cesación de pagos, pero no con el objeto de accionar legalmente sino más bien con la intención de negociar y obtener prontas ganancias en las reestructuraciones de deuda que eventualmente los emisores lleven a cabo. Estos inversores claramente se constituyen como uno de los actores más perversos de la globalización financiera. 
demandantes junto al pago a los bonistas reestructurados. Obviamente, y como era de esperarse, el gobierno argentino apeló la decisión del juez Griesa. Sin embargo, el 26 de octubre de 2012 la Cámara de Apelaciones del Segundo Circuito de Nueva York confirmó la decisión de primera instancia. Finalmente, el 16 de junio de 2014 la Corte Suprema de Estados Unidos optó por rechazar el pedido del gobierno argentino, dejando así firme el fallo de primera instancia del Juez Griesa, por medio del cual se obligaba a la Argentina a pagar una suma de alrededor de 1.600 millones de dólares, resultante del reconocimiento para los demandantes del $100 \%$ del valor de la deuda en su poder más intereses y punitorios.

A diferencia de la etapa anterior, el fenómeno externo coincidió con un momento de debilidad económica de la Argentina (KULFAS, 2014; DAMIL y FRENKEL, 2014). Para el año 2012 la Argentina tenía un grave problema de la restricción externa (mayor demanda que oferta de dólares) como consecuencia de desequilibrios macroeconómicos y de un menor ingreso de divisas por el canal exportador. Para fines del 2013 era evidente la necesidad de volver a utilizar la herramienta del endeudamiento externo (máxime en un mundo de bajas tasas de interés ${ }^{13}$ ). En otras palabras, parecía ineludible dejar atrás la prescindencia de la globalización financiera. En tal sentido, el gobierno argentino comenzó a transitar por una estrategia denominada la "agenda del crédito". Asumió una actitud más dialoguista y de acercamiento con el FMI, a los fines de acordar la confección de un nuevo índice de precios al consumidor. Además, en octubre de 2013 accedió a cerrar otro frente de conflicto, al lograr un acuerdo con cuatro empresas que tenían fallos favorables con sentencia firme en el Centro Internacional para el Arreglo de Diferencias relativas a Inversiones (CIADI). También se acordó con una quinta empresa que había litigado en el marco de la Comisión de las Naciones Unidas para el Derecho Mercantil Internacional (CNUDMI).

En el plano interno, los desequilibrios macroeconómicos condujeron al gobierno a implementar algunas políticas de ajuste demandadas por el mercado. Tal fue el caso de la devaluación de un $20 \%$ de la moneda en enero de 2014 y la suba de la tasa de interés de referencia de un $15 \%$ a un $29 \%$. En tal contexto, se agudizó aún más la necesidad de resolver el frente externo y eventualmente recuperar el acceso al mercado internacional de capitales a tasas razonables. En consecuencia, el 29 de mayo de 2014 Argentina llegó a un acuerdo con el Club de París para regularizar la deuda que mantenía con los países acreedores nucleados en dicho foro, la cual se encontraba en default desde diciembre de 2001. Como se puede apreciar, Argentina aceptó hacer aquello que había resistido en años anteriores y en pocos meses avanzó de manera consistente y decidida en la resolución de las cuestiones pendientes del default. Sin embargo, la referida decisión de la Corte Suprema de Estados Unidos y la consecuente confirmación del fallo de Griesa, supusieron un nuevo obstáculo para regresar a la globalización financiera que fue, sin lugar a dudas, la principal implicancia del fallo. La Argentina seguía marginada del mercado de capitales internacional aunque ahora ya no por propia elección (ACTIS y CREUS, 2015).

El triunfo de los fondos buitres en la justicia norteamericana no solamente impactó sobre la política económica y el largo proceso de reestructuración de deuda ${ }^{14}$ sino que además constriñó a la PEA. Como lo señalamos en el primer apartado, el vínculo bilateral con los

\footnotetext{
${ }^{13}$ Una vez superada la crisis financiera internacional, las principales economías desarrolladas seguían con un crecimiento económico anémico. En ese marco, tanto la Reserva Federal de los Estados Unidos como el Banco Central Europeo mantuvieron a la baja las tasas de interés (prácticamente tasas negativas). A partir del 2010 la liquidez internacional se trasladó a los países emergentes en búsqueda de mayor rentabilidad. En esa coyuntura, los países latinoamericanos pudieron emitir deuda en los mercados internacionales en torno a una tasa promedio de entre 3 y $5 \%$ anual.

${ }^{14}$ Como bien señalaron las autoridades argentinas, el cumplimiento inmediato del fallo de Griesa ponía en jaque todo el proceso de restructuración de deuda, en tanto que los bonos reestructurados contenían una cláusula denominada Rights Upon Future Offers (RUFO), la cual establecía que cualquier mejora que realizara la Argentina de manera voluntaria a aquellos acreedores que no habían ingresado en los canjes de 2005 y 2010, debería ser extensiva para todos los demás. La fecha de expiración de la misma era el 31 de diciembre de 2014, impidiendo por tanto la posibilidad de dar una solución hasta pasada esa fecha a los fines de no alterar las condiciones de la deuda reestructurada.
} 
Estados Unidos volvió a resentirse producto del convencimiento de la administración argentina de que la Casa Blanca no había hecho todo lo posible para interceder por la posición argentina ${ }^{15}$. Por su parte la irrupción de este nuevo condicionante externo de la globalización financiera conllevó a que la Argentina profundizase su vínculo con la República Popular China (VADELL, et. al. 2016) ya no solamente por la vía del canal comercial sino también en el eje financiero. En julio de 2014, el Banco Central de la República Argentina (BCRA) firmó con el Banco Central de República Popular de China un acuerdo de swap de monedas locales por un monto de 11 mil millones de dólares. El swap le permitió al gobierno de Cristina Kirchner robustecer las reservas internacionales y garantizar divisas para afrontar las necesidades de su último año de gestión.

\section{Las variaciones en el comercio internacional y su influencia sobre la PEA}

Otro de los condicionantes externos significativos de la larga década kirchnerista ha sido el de la globalización comercial. El carácter de la misma ha variado a lo largo de los años pasando de un marco de mayor permisibilidad a uno de creciente restricción para una PE autonomista, del tipo de la que buscaron plantear las gestiones del período 2003-2015.

Al asumir Néstor Kirchner la globalización estaba ingresando a una etapa de inusual dinamismo. Tras el receso económico de 2001, en el 2002 hubo una gran expansión del comercio mundial, en la que los nuevos motores de la economía internacional comenzaban a sobresalir, dando lugar a un nuevo escenario internacional. Este escenario fue permisivo para la recuperación económica del país, para la búsqueda de una diversificación de la canasta del comercio exterior y de los socios comerciales externos y para el ejercicio de una PE multilateralista y reformista del sistema internacional. Una serie de factores han incidido en ello: en primer lugar, destacamos el crecimiento de las importaciones de los países en desarrollo de Asia y de las economías en transición, que se sumaron a los Estados Unidos como los actores más dinámicos en los flujos del comercio global a principios del siglo XXI. En particular China se convirtió en un actor central tanto en términos de importador como de exportador, siendo que ya en 2003, el ritmo de crecimiento de las exportaciones de mercancías de China duplicó al de las exportaciones mundiales. Otro factor de crecimiento del comercio internacional fue el alza de los precios de los productos básicos: tanto los precios de los productos agropecuarios como de las industrias extractivas comenzaron a aumentar con mayor rapidez que los precios de los productos manufacturados. Por último, durante estos años comenzó a plasmarse un incremento en el comercio exterior de los bienes intermedios, las partes y componentes, que implicaron que la producción y el comercio mundial se ordenasen en "cadenas globales de valor".

Como resultado de estos aspectos se configuró una tendencia que fue característica fundamental del contexto en el que se desarrolló la PE del kirchnerismo: el comercio internacional comenzó a crecer con mayor intensidad que la evolución de la producción mundial. La globalización de acentuó y nuevos actores -fundamentalmente países en desarrollose incorporaron a las dinámicas del comercio internacional, ya no exclusivamente centradas en Estados Unidos y la Unión Europea. Estos cambios impactaron en la manera en la que se articuló la política comercial externa de la Argentina, generando un contexto de permisibilidad para la dimensión comercial de la PE, la cual se plasmó formalmente en el año 2004, en un documento del Ministerio de Economía de la Nación. El incremento de los mercados permitió al gobierno de Kirchner plantear principios tales como el de la multipolaridad (entendida como

\footnotetext{
${ }^{15}$ En un primer momento, Washington adoptó una postura de apoyo hacia el país, a través de un escrito presentado por los Departamentos del Tesoro y de Estado ante la Corte de Apelaciones de Nueva York pidiendo una revisión total del fallo de octubre de 2012 y, en particular, de la interpretación de que Argentina violó la cláusula de tratamiento igualitario a los acreedores. Sin embargo, este primer acompañamiento no se ha replicado ante el recurso extraordinario presentado por el gobierno argentino a la Corte Suprema de Justicia estadounidense. En este caso Washington no lo hizo por sí mismo e impidió que lo realizara el FMI, cuya titular había expresado la voluntad del organismo para hacerlo. Finalmente, EE.UU tampoco votó la resolución presentada por Argentina ante la Asamblea de ONU para establecer algunas normas básicas en los procesos de renegociación de deuda soberana (BUSSO, 2014).
} 
desconcentración geográfica); la reciprocidad (como el equilibrio entre las concesiones que la Argentina otorga y aquellas que recibe); y el pluritematismo (en términos de diversificación de producto) (MECON, 2004).

La diversificación de las exportaciones, considerada clave para una PE autonómica (SIMONOFF, 2010) sólo resultó posible en este contexto de inédito crecimiento de la globalización comercial. En efecto, existió una demanda externa en expansión: "la participación de las exportaciones de las economías en desarrollo en el comercio mundial aumentó del $26 \%$ en 1995 al 44\% en 2014, mientras que la participación de las exportaciones de las economías desarrolladas disminuyó del 70\% al 52\%" (OMC, 2015).

Estos nuevos mercados contribuyeron a su vez a modificar la geografía política de las relaciones comerciales internacionales, siendo que algunos países en desarrollo comenzaron a ocupar lugares influyentes en la regulación de los asuntos mundiales. De hecho, la emergencia de la coalición del G20 en la Conferencia Ministerial de Cancún, en el seno de la OMC, fue posible debido a la mayor importancia de los países en desarrollo en el comercio mundial. Esta coalición posibilitó luego la presencia de actores como Brasil y Sudáfrica en las reuniones informales donde el grueso de la negociación de los temas comerciales es llevado a cabo. Para la Argentina, ello resultó favorable en orden a concretar ciertos ajustes en su posición dentro de la OMC, pasando de una postura tradicional de liberalización del comercio agrícola a una más de tipo desarrollista donde se combinó la persecución de objetivos de apertura comercial en agricultura como flexibilidades especiales y trato especial y diferenciado en bienes industriales. Las coaliciones, producto de esta nueva geografía, permitieron a su vez obtener mayor posibilidad de participación real en las negociaciones, siendo Argentina parte del G20 ya mencionado, y de la coalición NAMA-11 durante el período analizado ${ }^{16}$.

En el plano latinoamericano esta diversificación de vínculos y nueva geografía del comercio internacional posibilitó una mayor coordinación de políticas con los socios regionales, que condujo, entre otros, al fortalecimiento del MERCOSUR, o bien, a posibilitar instancias como las del rechazo del ALCA, en el año 2005.

Otro aspecto inicialmente permisivo para la PE del país fue el crecimiento de China. Al menos hasta el año 2007 puede considerarse que el ascenso de esta potencia asiática fue benigno para la Argentina en tanto contribuyó fuertemente a incrementar la demanda externa, directa -a partir de la compra de soja y derivados-- como indirecta -a partir del efecto que tuvo en otras economías de la región latinoamericana--; a la vez que explicó de forma sustancial el incremento de los precios de los commodities agrícolas. Incluso, en años críticos, como el 2007, donde el comercio mundial se desaceleró por el debilitamiento de las economías desarrolladas, Argentina pudo mantener una política autonomista en función del volumen de la demanda y la diversificación que provocó China en la composición de los socios del comercio exterior del período ${ }^{17}$. Dando cuenta de tal relevancia puede destacarse, como ya mencionamos en la primera parte de este artículo, la visita de Kirchner a China, y de Hu Jintao a Argentina en 2004, así como el memorándum firmado por ambos países en el cual Argentina reconoció la condición de "Economía de Mercado" de China ${ }^{18}$.

La suba de los precios de los commodities, por su parte, fue fundamental para los niveles de crecimiento económico de la Argentina desde el comienzo de las administraciones

\footnotetext{
16 Véase Zelicovich, 2015. El G20 reúne a países en desarrollo interesados en los avances de las negociaciones agrícolas, tales como Argentina, Bolivia, Brasil, Chile, China, Cuba, Ecuador, Egipto, Filipinas, Guatemala, India, Indonesia, México, Nigeria, Pakistán, Paraguay, Perú, Sudáfrica, Tanzania, Tailandia, Uruguay, Venezuela, Zimbabwe. Por su parte, la coalición del NAMA-11 está compuesta por países en desarrollo comprometidos con el aspecto del "desarrollo" de la Agenda de Doha, especialmente en el pilar del Acceso a Mercados para bienes No agrícolas. La integran Argentina, Brasil, Egipto, India, Indonesia, Namibia, Filipinas, Sudáfrica, Túnez y Venezuela.

${ }^{17}$ Debe señalarse además que en el año 2007 las exportaciones de productos agrícolas se incrementaron $19,5 \%$ en dólares, lo que constituye la tasa de crecimiento más alta desde 2000. En ese año, América del Sur y Central registraron su tasa de crecimiento más elevada desde 2000.

${ }^{18}$ Véase Paz (2013).
} 
kirchneristas. Si bien tal como señalan Damill y Frenkel, la contribución del alza del precio de los commodities fue posterior a la reversión del ciclo económico de la Argentina, este incremento luego sería clave en el sostenimiento de la tendencia (DAMILL y FRENKEL, 2015). Así, según la OMC, "la evolución de los precios fue con frecuencia el principal factor que contribuyó al dinamismo relativo de las corrientes comerciales en 2004". Este contexto fue clave para impulsar una política fiscal basada en impuestos a las exportaciones agrícolas que permitió mantener los superávits gemelos, expandiendo la demanda doméstica y posibilitando las bases de un modelo económico de corte neodesarrollista, que se articuló con la PE mencionada supra.

Sin embargo, llegado el 2008 este círculo virtuoso externo se revirtió. La crisis de las hipotecas subprime fue el puntapié para que este contexto permisivo se transformara de manera incremental en uno restrictivo para la PE de los Kirchner, algo que se produciría de manera gradual. Al igual que la globalización financiera, la globalización comercial ingresó en un momento sistémico restrictivo. El comercio actuó como un multiplicador de la crisis, y si en los años previos su crecimiento duplicó al del PBI, lo mismo sucedió durante la contracción económica internacional. En 2009 el comercio se desplomó de manera sustantiva. Conforme a la OMC (2010) "El abrupto descenso del comercio se debe a una conjunción de factores, como la debilidad de la demanda, la disminución de los precios de los productos básicos, la presencia de cadenas de abastecimiento mundiales, el impacto simultáneo de la crisis económica en los distintos países y regiones y las dificultades para acceder al crédito [privado] en general y a la financiación para el comercio en particular".

En tanto los países en desarrollo -fundamentalmente los asiáticos- tuvieron una primera recuperación más pronta que los países desarrollados occidentales, Argentina continuó con su política de diversificación de vínculos ${ }^{19}$, pero los resultados fueron ambiguos.

Por un lado, se mantuvieron efectos permisivos. Tal como señala Villamar (2016), la crisis de 2008 reforzó la impresión acerca del poder global en beneficio de las potencias emergentes. Ello dio eco al discurso argentino de reforma del sistema internacional ${ }^{20}$, el cual pudo plasmarse, entre otros, en las cumbres de Jefes de Gobierno del Grupo de los 20 (g-20).

También fue permisivo, como señalamos al comienzo del trabajo, el efecto de la profundización del alza de los precios de los commodities. Estos se redujeron levemente en 2009 pero volvieron a experimentar un nuevo nivel de ascenso a partir de 2010, con su máximo histórico en 2011. Ello permitió al gobierno argentino mantener un ingreso sustantivo de dólares producto de las ventas al exterior de soja y derivados, así como continuar experimentando niveles de demanda en otros rubros. El mantenimiento sostenido de los precios permitió también impulsar otras acciones en la PE vinculada al comercio global. En particular, permitió fortalecer las posturas desarrollistas en la posición negociadora en la OMC, y mostrarse más concesivo en las negociaciones de acceso a mercados agrícolas, puesto que desde el gobierno se entendía que a los efectos buscados en tal área "hay cosas que van a ocurrir con o sin negociación" $"$.

Sin embargo, otros factores internacionales comenzaron a volverse restrictivos. En el caso de la relación comercial con China, el incremento de las asimetrías llevó a plasmar una dinámica de vinculación de tipo norte-sur y comenzaron a verse rasgos de vulnerabilidad para la inserción internacional de Argentina en este vínculo. Para el año 2008 China ya había desplazado a otros países como principales socios comerciales de la Argentina, pero a diferencia

\footnotetext{
${ }^{19}$ En 2009 China sobrepasó a Alemania como mayor exportador mundial de mercancías y en segundo importador del mundo.

${ }^{20}$ En particular, en el ámbito del comercio internacional, lo que se buscaba era que la OMC se orientara a "la defensa de los derechos de los países emergentes a cuidar sus procesos de industrialización y a tener una negociación equitativa entre países en desarrollo y países desarrollados" (Fernández de Kirchner, 2010).

${ }^{21}$ Véase El gobierno privilegia la industria frente al agro en la OMC, edición impresa La Nación, Buenos Aires, 13 de junio de 2007. Disponible en: http://www.lanacion.com.ar/916948-el-gobierno-privilegia-ala-industria-frente-al-agro-en-la-omc
} 
de aquellos el intercambio con este país presentaba dos componentes adicionales: la balanza comercial resultaba claramente deficitaria para Argentina y las exportaciones de argentinas a China sólo se centraban en 4 productos de muy poco valor agregado. Ello conllevó a una marcada primarización de la economía ${ }^{22}$ y a situaciones donde se plasmó una interdependencia asimétrica desfavorable para la Argentina, como en la suspensión de importación de aceite de soja del año $2010 .^{23}$

En materia de comercio internacional, desde 2008 un mayor proteccionismo mundial se combinó con una mayor vigilancia de los instrumentos aplicados, lo cual derivó en una mayor sofisticación de las barreras comerciales ${ }^{24}$. Argentina fue señalada en diversos estudios por el fuerte incremento en los instrumentos de administración del comercio y protección comercial que implementó y ello derivó en el inicio de una controversia en la OMC en el año 2012. Si bien los plazos fueron largos el contexto terminó restringiendo el margen de maniobra para la política comercial externa del país ${ }^{25}$.

Del lado de las negociaciones comerciales, en simultáneo a este proceso de complejización de las políticas comerciales, los grandes actores del sistema internacional dejaron de lado a la OMC como foro principal para la regulación del comercio mundial y se orientaron a iniciativas preferenciales megarregionales. En 2009 se lanzaron las negociaciones del Acuerdo Transpacífico ${ }^{26}$, en 2012 las de la Asociación Económica Integral Regional (RCEP, su sigla en inglés) ${ }^{27}$ y en 2013 las del tratado transatlántico, entre Estados Unidos y Europa. Este escenario fue desfavorable para la Argentina en tanto quitó relevancia y dinamismo a las negociaciones de OMC y, además, condicionó otras negociaciones que desde 2011 Argentina quiso re-impulsar como las del tratado de libre comercio MERCOSUR-Unión Europea.

Conjuntamente, a partir de 2011, la recesión económica mundial se acentuó debido a la crisis europea y el comercio comenzó a ralentizarse. Brasil, por su parte, otro de los socios comerciales importantes de Argentina también empezó a exhibir un menor desempeño de la economía. Conforme a datos de la OMC, de 2012 a 2014 la tasa media de crecimiento del valor del comercio de mercancías fue solo del $1 \%$, en tanto que "la tasa de crecimiento de las exportaciones de mercancías bajó del 14,0\% al 2,0\% entre 2010 y 2012, mientras que la tasa de crecimiento del PIB disminuyó del 4,0\% al 2,0\% durante el mismo período" (OMC, 2012: 14). En consecuencia, las exportaciones argentinas se vieron afectadas más allá de los factores de competitividad -inflación- por una restricción de la demanda externa.

Debe considerarse que en 2011, casi la mitad (el 49\%) del comercio mundial de mercancías y servicios se llevó a cabo a través de cadenas de valor mundiales, frente a un 36\%

\footnotetext{
${ }^{22}$ Sobre esto véase Roldan Perez, et. al., 2016.

${ }^{23}$ China aprovecha esta situación y usa su mejor condición para presionar frente a distintas políticas argentinas. Así por ejemplo en 2010 suspende la importación de aceite de soja proveniente de este país.

${ }^{24}$ Véase Baldwin y Evenett (2009).

${ }^{25}$ El proceso contra la Argentina -que agrupó cuatro reclamos, DS438, DS444, DS445 y DS446- se inició en mayo de 2012 con el establecimiento de consultas entre las partes, luego de que Australia, la UE, Israel, Japón, Corea, México, Nueva Zelanda, Noruega, Panamá, Suiza, Taiwán, Tailandia, Turquía y EE.UU. presentaran ante el Consejo del Comercio de Mercancías de la OMC una declaración conjunta contra el país. El informe del Grupo Especial se distribuyó en agosto de 2014, concluyendo que tanto las Declaraciones Juradas Anticipadas de Importación (DJAI) como las prescripciones relacionadas con el comercio cuestionadas por los peticionantes constituían una restricción a la importación, debiendo la Argentina desarticular estas medidas. Luego de que el Órgano de Apelaciones confirmara lo dispuesto por el Grupo Especial, se acordó como plazo para la adopción de las recomendaciones diciembre de 2015.

${ }^{26}$ Este acuerdo tiene su antecedente en el Acuerdo Estratégico Transpacífico de Asociación Económica (P4) firmado por Brunei, Chile, Nueva Zelanda y Singapur en el año 2006. En 2009 se iniciaron negociaciones para extender ese acuerdo más allá de los cuatro miembros originales incorporando a Australia, Estados Unidos, Malasia, Perú y Vietnam en lo que se dio en llamar el Acuerdo Transpacífico. Posteriormente se unieron a las negociaciones Canadá, Japón y México, hasta alcanzar un total de doce países que representan una cuarta parte del comercio mundial.

27 Forman parte de este acuerdo Malasia, Indonesia, Brunei, Vietnam, Camboya, Laos, Myanmar, Singapur, Tailandia, Filipinas, Australia, China, India, Japón, Corea del Sur y Nueva Zelandia.
} 
en 1995. Esta tendencia a la intensificación de la especialización vertical no contribuyó en la inserción internacional de Argentina, en tanto que factores estructurales como la distancia geográfica a las tres grandes fábricas mundiales y las características del mercado doméstico han hecho que la participación del país dentro de las cadenas globales de valor sea relativamente reducida. De tal forma, el grueso de las exportaciones argentinas con valor agregado no pudo traspasar la región latinoamericana, en tanto que se consolidó la primarización de las exportaciones hacia el resto del mundo.

Asimismo, el elevado nivel de los precios de los commodities comenzó a tener una cara negativa. El incremento de los precios del petróleo fue mayor al del de los commodities agrícolas, generando un efecto negativo en la balanza de pagos de la Argentina. Por ejemplo, según datos de la UNCTAD, mientras que en el año 2012 los precios de las semillas y sus derivados bajaron un 8\%, el precio de barril de crudo subió 1\%, en relación a 2011.

El último año del kirchnerismo experimentó un nivel de restricción mayor a todo el período previo en lo que hace a la globalización comercial. El comercio internacional creció solo $2.7 \%$. Los precios de la soja y sus derivados experimentaron un descenso de $20 \%$, pero a la vez, el precio del petróleo cayó un 47\%, deprimiendo la demanda externa regional. China, cambió su patrón de producción y exportación, sustituyendo los insumos importados por otros de producción nacional (ROLDAN PÉREZ, et. al, 2016). Asimismo, según datos del Banco Mundial, el promedio de crecimiento anual de las economías BRICS se redujo a la mitad en 2015, comparado con $2010^{28}$. En este contexto, los principios de la política comercial externa planteados 10 años antes (pluritematismo, reciprocidad y diversificación) resultaban imposibles de ser concretados.

\section{El cambio parcial en la seguridad hemisférica y su impacto sobre la PEA}

El desarrollo de los gobiernos kirchneristas se desplegó en un contexto mundial donde las cuestiones estratégico-militares estuvieron marcadas por el cambio del paradigma en la seguridad internacional a partir de los atentados del 11 de septiembre. A nivel hemisférico, la incidencia que tuvieron los condicionantes externos en la configuración de la PEA dejó traslucir ese escenario de cambio aunque no de manera absoluta dada la permanencia de ciertas premisas tradicionales que rigen los vínculos interestatales continentales en la dimensión estratégicomilitar. De este modo, se identifica como condicionantes externos del diseño y ejecución de la PEA kirchnerista al cambio parcial en la seguridad hemisférica, siendo sus indicadores: la aceleración del proceso de erosión de la arquitectura de seguridad interamericana, el deterioro de la imagen de Estados Unidos y la consolidación de un escenario intrarregional de paz interestatal.

Asimismo, el impacto de los condicionantes sistémicos sobre la PEA fue virando de manera progresiva a lo largo de los doce años de gobierno kirchnerista desde una mayor permisividad hacia la preponderancia de un efecto restrictivo. Al respecto, si bien resulta difícil delimitar temporalmente estos dos períodos, la intensidad del efecto permisivo fue disminuyendo con el paso del tiempo y, concluida la primera década del siglo XXI, comenzó a primar un ambiente internacional con rasgos restrictivo sobre la PEA. Consecuentemente, para finales de 2015 encontramos cursos de acción que habían perdido su impulso inicial así como proyectos que acabaron sin presentar resultados concluyentes.

Analizando el cambio parcial de la variable seguridad hemisférica, podemos afirmar que el indicador relativo a la aceleración del proceso de erosión de la arquitectura de seguridad

\footnotetext{
28 Acorde a Villamar (2016) “A partir de 2014 los factores de la ralentización fueron cada vez más identificados como internos: volatilidad de la moneda y de los mercados financieros locales, dificultades en las finanzas públicas con déficit y deudas en aumento; menor margen de maniobra en la política monetaria debido en parte a la inflación que excedía los objetivos previstos; una reducción de la estimación de la productividad total de los factores; en suma, la caída de perspectivas positivas".
} 
interamericana afectó los vínculos cooperativos interestatales, favoreciendo la subregionalización del diálogo y la cooperación en esos temas ${ }^{29}$.

En este sentido el empleo de herramientas como la Junta Interamericana de Defensa (JID), el Tratado Interamericano de Asistencia Recíproca (TIAR) y el Pacto de Bogotá estaba limitado por sus propósitos asincrónicos, la aceptación heterogénea y dispar de los Estados y las opiniones desfavorables sobre su vigencia ${ }^{30}$. A ello se adicionó la profundización del desvanecimiento de América Latina como esfera de influencia homogénea de Estados Unidos. Este proceso se aceleró durante el siglo XXI particularmente en América del Sur donde prevaleció el giro político-ideológico de la mayoría de los estados hacia gobiernos de centroizquierda. La retórica política de estos gobiernos instaló una concepción multidimensional de la seguridad que ligó las problemáticas estructurales socio-económicas con la proliferación de los desafíos a la seguridad de los individuos y los estados e impulsó la adopción de herramientas distintas al uso de la fuerza militar para combatir las amenazas. Por su parte Estados Unidos, si bien compartía la nueva mirada multidimensional sobre la seguridad, incentivó a terceros países a aplicar mecanismos de respuesta a las amenazas anclados en el instrumento militar y entendió que el Estado es el único proveedor y recipiendario de tal seguridad, respaldando la vigencia del esquema hemisférico. Finalmente, la falta de una agenda de seguridad compartida con temas ordenados jerárquicamente se plasmó en la "Declaración sobre seguridad en las Américas" (2003) ilustrando la fragmentación de la dinámica de seguridad continental, lo cual dificultó un acercamiento cooperativo interestatal a gran escala y acrecentó la capacidad de los estados latinoamericanos para establecer sus propias agendas con mayor autonomía.

Un segundo indicador, en articulación con el primero, es el deterioro de la imagen de Estados Unidos. A pesar de su rol tradicional como poder hegemónico continental, el despliegue de su PE pos $11 \mathrm{~S}$ afectó su credibilidad. Esta adquirió un carácter unilateral y militarista, que habilitó las acciones preventivas, privilegió el aparato de inteligencia, impulsó un aumento exponencial del presupuesto de defensa y otorgó preeminencia al interés nacional transformando el cumplimiento de sus compromisos multilaterales en una suerte de multilateralismo a la carta (BUSSO, 2005). Frente a esto, la mayoría de los países de la región rechazaron la invasión a Irak de 2003 y reprobaron el involucramiento explícito de Washington desde 2002 en el conflicto colombiano, permitiendo que los fondos del Plan Colombia se utilicen para combatir a los grupos armados, asistir la implementación de los planes Patriota y Victoria y, finalmente, arrendar varias bases militares. En este contexto, particularmente los estados de Sudamérica, condenaron enfáticamente el ataque de las Fuerzas Armadas colombianas en Angostura en 2008 cuyos fundamentos reproducen la doctrina preventiva norteamericana. Además, manifestaron sus resquemores frente a la clasificación de los Departamentos de Estado y de Defensa del Cono Sur como una zona de amenaza potencial en virtud de la situación en la Triple Frontera, la debilidad estructural del Paraguay y el deterioro de las capacidades de control sobre las fuerzas de seguridad por parte de los estados (BUSSO, 2005). Por último, hay que considerar la continuidad de una política contra el tráfico de drogas cuyas premisas y modalidad no ha devenido en resultados positivos que equivalgan al presupuesto invertido, pero que sí dieron lugar a dudas razonables con respecto a los

\footnotetext{
${ }^{29}$ La sub-regionalización de la cooperación se consolida a pesar de los cambios en la Organización de Estados Americanos como la creación de la Comisión de Seguridad Hemisférica en 1995 y la Secretaria de Seguridad Multidimensional en 2005. Ejemplo de ello son la Conferencia de Fuerzas Armadas Centroamericanas (1997) y la Estrategia de Seguridad Centroamericana (2007); así como el direccionamiento de los programas de cooperación norteamericanos como la Iniciativa Mérida (2007), la Iniciativa Regional de Seguridad para Centroamérica (2008) y la Iniciativa de Seguridad de la Cuenca del Caribe (2010); siendo la nota más destacada la creación del CSD en (2008).

${ }^{30}$ Considerando que la OEA cuenta con 35 estados miembros, cabe reflexionar sobre el hecho de que la JID está conformada por 27 estados de los cuales en 2013 se retiraron Venezuela, Bolivia, Nicaragua y Ecuador; el TIAR cuenta con 21 integrantes y en 2001 se retiró México y, en 2012, Bolivia, Ecuador, Venezuela y Nicaragua; y de los 21 miembros del Pacto de Bogotá, solo 16 estados lo ratificaron ( 8 de ellos con reservas -Argentina, Bolivia, Ecuador, Estados Unidos, Nicaragua, Paraguay, Perú y Chile-), El Salvador (1973) y Colombia (2012) lo denunciaron mientras que Belice, Chile, Panamá y Perú dialogaron sobre la conveniencia de revisarlo, y Ecuador y Venezuela plantearon sustituirlo.
} 
instrumentos empleados, entre ellos la reactivación de la cuarta flota en 2008 y los objetivos estratégicos norteamericanos en la región ligados con el control y el acceso rápido al territorio (MILITARY CONSTRUCTION PROGRAM, 2009).

El tercer y último indicador es la consolidación de un escenario intrarregional de paz interestatal ya que América Latina es reconocida internacionalmente, desde la restauración democrática, como una zona de paz por el nivel bajo de conflictividad interestatal y en 2014 fue proclamada como tal por la CELAC ${ }^{31}$. Más específicamente, en América del Sur, si bien los avances más significativos se sucedieron durante los años $90^{32}$, con la llegada del nuevo siglo se fortalecieron las Medidas de Fomento de la Confianza Mutua y los lazos cooperativos aunque con diferentes grados de intensidad y características. Esto acontece tanto en el marco institucional de los procesos de integración de la CAN y el MERCOSUR como a nivel bilateral y multilateral mediante la constitución de grupos de trabajos y mecanismos de diálogo ${ }^{33}$. Por tanto, las hipótesis de conflictos tradicionales se fueron suavizando con la transparencia en la información sobre presupuestos, efectivos, equipos y objetivos militares plasmada en los libros blancos o documentos similares, y con las prácticas de ejercicios militares combinados.

A partir de las características de los indicadores expuestos podemos argumentar que los gobiernos kirchneristas transcurrieron inicialmente dentro un marco internacional con un grado de permisibilidad considerable. El mismo les facilitó plantear una política de Defensa con lineamientos externos que, sustentados en la premisa de la derogación de las hipótesis de conflicto, se dirigieron a instaurar un modelo defensivo, autónomo y cooperativo, que tuvo a Sudamérica como área prioritaria de acción externa y a Latinoamérica como segundo círculo de interés estratégico (DECRETO 1714, 2009).

Estos lineamientos se sustentaron en la propuesta autonomista que los gobiernos de Néstor y Cristina tuvieron para la PE y, desde lo discursivo, se llevaron adelante articulando una retórica política de defensa de los derechos humanos, no proliferación nuclear, apoyo al multilateralismo a través de la defensa del rol de Naciones Unidas en cuestiones de paz y seguridad internacional y del accionar de las Operaciones para el Mantenimiento de la Paz. En este marco, por otra parte, el vínculo con Washington se fue resintiendo porque, si bien Argentina lo acompañó en la lucha contra el terrorismo internacional, criticó cada vez con mayor dureza las premisas basales de su comportamiento externo relativo a esa lucha y se pronunció a favor de la defensa de los principios de soberanía, no injerencia e integridad territorial en coyunturas de crisis de distinta índole (invasión norteamericana a Irak, bombardeo colombiano en Angostura, intervención de la OTAN en Libia, entre otras).

Consecuentemente, el kirchnerismo durante la primera década del siglo XXI encontró un contexto propicio para su intención de fortalecer la UNASUR como bloque susceptible de consensuar posiciones comunes sobre los asuntos de paz y seguridad internacional. Incluso, le adicionó a las Fuerzas Armadas una cuarta tarea subsidiaria ligada a su contribución con el proceso de construcción de un sistema de Defensa subregional (DECRETO 1691, 2006). También apoyó la creación del CDS en 2008 participando activamente para concretar sus planes de acción y propuso la creación del Centro de Estudios Estratégicos de Defensa en 2009. Al respecto, el ex canciller Taiana afirmó que "Fue una clara demostración de la vocación y la voluntad política de la región por avanzar en la integración y en la reafirmación de la autonomía

\footnotetext{
${ }^{31}$ América Latina es la región del mundo que menos porcentaje de su PBI gasta en Defensa; los niveles de inversión en el sector son los menos relevantes del planeta; no existe una amenaza tradicional extraregional y, desde el retorno a la democracia, la supremacía civil sobre las Fuerzas se ha ido propagando.

32 En los 90 se resolvieron los principales contenciosos fronterizos; finalizó la competencia militar estratégica entre los actores de mayor peso; tuvo lugar la Declaración de Ushuaia y el Plan General de Cooperación y Coordinación Recíproca para la Seguridad Regional en el MERCOSUR, Bolivia y Chile.

${ }^{33}$ En América del Sur, además de los acuerdos bilaterales y multilaterales, se destacan: el Compromiso de Lima (2002); la Declaración de Guayaquil (2002); la Declaración de San Francisco de Quito (2004); los Lineamientos de la Política de Seguridad Externa Común Andina (2004); la Declaración Política del Mercosur, Bolivia y Chile como Zona de Paz (2014).
} 
regional frente al avance de los poderosos" ${ }^{34}$. Por otra parte, a nivel regional, Argentina propuso establecer la Asociación Latinoamericana de Centros para Operaciones de Paz en 2007 y participó en el mecanismo "2x9" para Haití.

En este marco, además, se buscó robustecer los vínculos de confianza mutua y cooperación con los estados sudamericanos en particular, y latinoamericanos en general, de manera bilateral para lo cual: se concretaron las experiencias de complementación e integración con Chile (2006) y Perú (2008), Cruz del Sur y la Compañía de Ingenieros General San Martín respectivamente; se suscribieron 29 acuerdos bilaterales con estados de la región, entre ellos el Tratado de Maipú con Chile (2009) y el Acuerdo Marco sobre Cooperación en Defensa con Brasil (2005), frente a 15 firmados con países del resto del mundo (MINISTERIO DE DEFENSA, 2015); se realizaron el $80 \%$ de los ejercicios militares combinados con estados sudamericanos, siendo el $30 \%$ con Brasil y el $27 \%$ con Chile y se concretó con Brasil el proyecto Gaucho, entre otros.

Este abanico de acciones de PE, que estuvieron en consonancia con la estrategia de inserción kirchnerista, mejoró el posicionamiento del país en la subregión y, en general, en América Latina desde la perspectiva de la generación de confianza mutua y el fomento del diálogo en los asuntos de defensa. No obstante, sus resultados suelen ser subvalorados a razón de argumentos que asocian una inserción internacional provechosa con el incremento de las cuotas de poder como sostiene Miranda (2012).

Además, como se adelantó a inicios del apartado, también debemos considerar que la permanencia de algunas premisas rectoras de los vínculos interestatales hemisféricos en la dimensión estratégico-militar, mitiga y relativiza la impronta permisiva de los condicionantes externos sobre la PEA. De este modo tanto la voluntad de liderazgo de Washington en las cuestiones de Seguridad y Defensa a nivel continental ${ }^{35}$, reafirmada particularmente a partir de la segunda administración Obama, como el hecho que el escenario de paz intrarregional no resultó totalmente provechoso para la consolidación de un "proceso de seguridad" (Fontana, 1996) ni anularon de manera definitiva las diferencias y dificultades entre los estados ${ }^{36}$, son

${ }^{34}$ El recuerdo de Taiana a la gestión de Kirchner en UNASUR, Infonews, 4 de mayo de 2015, Buenos Aires. Disponible en: http://www.infonews.com/nota/198021/el-recuerdo-de-taiana-a-la-gestion-dekirchner-en-unasur Consulta: 16 de marzo de 2017.

${ }^{35}$ La voluntad de liderazgo norteamericano se ilustra a través de su propuesta de aplicar un modelo de seguridad cooperativa; la instauración de la Conferencia de Ministros de Defensa de las Américas; la convocatoria en 2013 de la Primera Reunión de Organizaciones Militares Interamericanas y sus propuestas con respecto a la JID. Por otro lado, América Latina, excepto México, es recipiendaria del accionar del Comando Sur cuyo objetivo estratégico es fortalecer las capacidades en seguridad a través del vínculo con los países y de posicionar a los Estados Unidos como un actor líder y aliado. Nótese que su presencia desde 1995 implica el empleo de la Fuerza de Tarea Conjunta Interagencial Sur y desde 2008 el retorno de la Cuarta flota. En igual sentido, el despliegue de distintas operaciones y ejercicios como la Operación Martillo, la Misión Promesa Continua, los ejercicios militares conjuntos Más allá del horizonte, así como los ejercicios militares combinados Fuerzas Comandos, PANAMAX, Partnership of the Americas, UNITAS, Tradewinds y Southern Partnership Station, entre otros. El país del norte, además, conserva a su favor una asimetría estratégico-militar insalvable en referencia a las capacidades materiales y técnico-profesionales que le permite concentrar las relaciones con la mayoría de las instituciones castrenses de la región y proponer iniciativas y planes de acción a los distintos gobiernos. El Plan Mérida, la Iniciativa Regional de Seguridad para Centroamérica, la Iniciativa de Seguridad Cuenca del Caribe, la Iniciativa de la Tercer Frontera y el Plan Colombia, entre los más relevantes. Finalmente, Washington mantiene y fortalece los canales de asistencia financiera directa y de venta de armas y los programas de entrenamiento y educación para las Fuerzas Armadas y de seguridad.

36 El escenario de paz intrarregional coexiste con: diferendos limítrofes y reclamos territoriales aún vigentes y susceptibles de generar una escalada de tensiones como ocurrió entre Perú y Ecuador en 1995; situaciones de tensión como las generadas entre Colombia y Venezuela y Ecuador entre 2008; la permanencia de hipótesis de conflicto entre estados más allá de sus discursos políticos y de la orientación ideológica que tengan sus gobiernos; la polaridad múltiple que conlleva disputas por el liderazgo regional o cuanto menos rispideces (BUZAN y WEBER, 2003); los efectos desestabilizadores de las amenazas transnacionales que pueden generar situaciones de roces en las zonas de frontera y que desvían la atención de los gobiernos hacia el abordaje prioritario de las agendas de seguridad pública; un devenir 
elementos de análisis relevantes. Al respecto, es ilustrativo el hecho de que pese a la creciente tensión en el vínculo con Washington -clarificada en un discurso cada vez más crítico y confrontativo por parte del gobierno nacional- las relaciones político-diplomáticas se mantuvieron y los gobiernos kirchneristas nunca renunciaron a participar en las instancias de cooperación interamericanas, la realización de ejercicios militares combinados con las Fuerzas norteamericanas en el exterior ${ }^{37}$ o al envío de personal militar nacional en el marco de los programas educativos de Estados Unidos. En igual sentido, se destaca la promulgación por el gobierno de Cristina de la Ley Antiterrorista en 2011 para evitar el lavado de dinero como fuente de financiamiento del terrorismo internacional.

Ahora bien, a partir de 2011 el contexto internacional permisivo se va tornando cada vez más rígido para Argentina, por lo que la promoción del diálogo sobre Defensa en la subregión, con identidad propia y en contraposición a los criterios de la potencia hegemónica regional, va perdiendo impulso. Esta tendencia está delineada preponderantemente por el incremento de la tensión en el vínculo Argentina-Estados Unidos luego del incidente de 2011 relativo a la requisa de un avión militar norteamericano en Ezeiza y la complejización de las realidades nacionales de varios de los estados de la subregión así como el corrimiento de las figuras centrales que promovieron el diálogo subregional como Chávez, Da Silva y Kirchner. Este conjunto de cuestiones también nos remite a una potenciación del condicionamiento que ejercen las premisas antes mencionadas, vinculadas a los rasgos más estructurales de las relaciones intra-continente.

En este contexto, durante el segundo gobierno de Cristina se concretaron algunos otros cursos de acción en un sentido distinto al de la promoción de un sistema de defensa sudamericano y del diálogo regional. Entre ellos se destacan los intentos por desarrollar vínculos más estrechos en Defensa con estados que mejoraron sustancialmente su lugar en la jerarquía internacional como Rusia y China, concentrándose acuerdos de cooperación, respectivamente, en 2014 y 2015 y en 2007 y 2012. Tales modificaciones en el discurrir de la PEA propiciaron análisis que se focalizan en señalar la pérdida del impulso que sufrieron ciertos cursos de acción ligados con el proyecto de inserción internacional con visos autonómicos, o el logro de resultados no concluyentes al respecto.

No obstante, por esos años, el kirchnerismo no sólo mantuvo su discurso oficial sobre la necesidad de promocionar la UNASUR y el CDS como ámbito de diálogo y cooperación, al igual que los vínculos bilaterales tradicionales, sino que continuó proyectando un accionar externo conducente con ello $^{38}$. Esto aconteció a pesar de: a- la impronta restrictiva que fue

poco promisorio de los procesos económicos-comerciales que contextualizaron los avances en los vínculos interestatales de confianza y cooperación en lo estratégico-militar; las disparidades en las capacidades militares y el incremento de la sensación de inseguridad de aquellos países que quedan en desventaja estratégica.

${ }^{37}$ Con respecto a los ejercicios militares combinados hay que aclarar que desde 2003 Argentina no ha recibido tropas norteamericanas para la realización de este tipo de actividades en función del rechazo de Estados Unidos a la Corte Penal Internacional y su exigencia de inmunidad para sus tropas.

${ }^{38}$ Entre 2011 y 2015 se realizan en Argentina los Ejercicios Conjuntos Combinado Regional de Operaciones de Mantenimiento de Paz "UNASUR"; desde 2014 FADEA participa de UNASUR Aero S.A., empresa regional a cargo de desarrollar el proyecto UNASUR I en Córdoba; y en líneas generales Argentina continuó participando y siendo sede de distintos eventos programados en los planes de acción anuales del CDS con igual intensidad que en los años previos a 2011. Por otra parte el vínculo con Chile se continúa fortaleciendo destacándose la creación en 2012 del Comité Ad-hoc para la coordinación política en materias antárticas y la primera reunión del Grupo de Trabajo Bilateral correspondiente al Programa Bilateral de Cooperación en Ciencia, Tecnología y Producción para la Defensa establecido por el acuerdo de Maipú. Mientras que con Brasil tuvo lugar la declaración conjunta de Ministros de Defensa en 2011 que pone en funcionamiento un mecanismo de diálogo político estratégico a nivel viceministerial; la firma en 2012 por parte de las Fuerzas Armadas de convenios dirigidos a incrementar la cooperación mutua a nivel logístico como de instrucción del personal militar en futuras maniobras conjuntas; en 2013 el Memorando de Entendimiento entre la Dirección de Puertos y Costas de Brasil y la Prefectura Naval Argentina para intercambio de experiencias e información; en 2014 la Declaración Conjunta Ministerial sobre la alianza entre las industrias de defensa de los dos países, que culminó en la 
adquiriendo el contexto internacional la cual, como mostramos en los apartados anteriores, tuvo manifestaciones políticas y económicas que sumadas a la permanencia de las premisas rectoras en los vínculos hemisféricos abordadas en este punto, tornaban menos visible o reducían el impacto de tales acciones; y b- el incremento de los análisis críticos que situaban la medida del éxito y fracaso de la inserción internacional del país y por ende de la PEA, únicamente en términos del incremento de las cuotas de poder.

\section{Conclusiones}

A lo largo del trabajo hemos tratado de mostrar cómo los condicionantes sistémicos operaron de manera permisiva para los objetivos autonomistas de la PEA en los años iniciales de la gestión kirchnerista, mientras que esa situación transitó hacia la restricción en los mandatos de Cristina Fernández, especialmente durante su segundo gobierno. La conexión que el gobierno estableció entre el perfil autonómico de la PEA y la necesidad de implementar un modelo económico neo-desarrollista a nivel interno hizo de la dimensión económica un dato central tanto en período permisivo como en el restrictivo y, por ello, las cuestiones de esa índole son las que reflejaron con más claridad el cambio de una situación a otra.

Como sostuvimos en este trabajo, desde finales de los años setenta hasta la actualidad, la globalización financiera se transformó en un condicionante para el desarrollo económico y la inserción internacional de todas las naciones, especialmente las periféricas. La particularidad de este condicionante, a diferencia de otros, es que adquirió un carácter estructural como componente del capitalismo actual y, por lo tanto, sus atributos para generar condicionalidad tienden a prolongarse en el tiempo. Consecuentemente, la Argentina re-democratizada sufrió ese constreñimiento de manera constante tanto a nivel de la economía nacional, como en el ámbito de la PE y las relaciones económicas internacionales. En este marco los gobiernos kirchneristas no han sido la excepción, por el contrario, durante los doce años de gestión los impactos de la globalización financiera se hicieron sentir de manera constante. La intensidad del impacto nos permitió distinguir tres etapas particulares (2003-2005; 2008-2010 y 2014-2015).

La nota distintiva de la primera etapa es la magnitud del impacto en tanto la PEA quedó prácticamente reducida al objetivo de salir del default, aunque finalizó exitosamente, con la primera renegociación en 2005. Sin embargo, a pesar de la envergadura del acuerdo, el problema no desapareció. Así, durante la segunda y tercera etapa se produce una particularidad caracterizada por una lógica invertida en relación a la configuración del sistema financiero internacional. Dicho de otra manera, en un momento sistémico altamente restrictivo (20082010) la Argentina pudo mantener (al igual que en la primera etapa) una relativa autonomía que le permitió disponer de mayores márgenes de maniobra en su PE. No obstante, en una coyuntura global permisiva de la globalización financiera para los países emergentes (20142015) nuestro país se vio condicionado fruto del poderío de un actor específico del sistema financiero (los fondos buitres) lo que condujo a una limitación y reorientación de algunas líneas de la PE, pero acentuó la convicción de profundizar la prescindencia de la globalización financiera y apostar a los beneficios de la globalización comercial.

Por otra parte, las variaciones en el comercio internacional muestran claramente que el aumento de la demanda global entre 2003 y 2008 fue muy significativo para que Argentina pudiera iniciar un proceso de recomposición económica. Condiciones externas tales como el incremento de las importaciones por parte de los países asiáticos en desarrollo; la suba del precio de los commodities y el nacimiento de una nueva geografía de las relaciones comerciales internacionales tuvieron un impacto positivo sobre la PEA ya que, tal cual lo hemos explicado, le permitió al Kirchnerismo plantear los principios de la multipolaridad; la reciprocidad y el pluritematismo. Con la crisis económico-financiera de 2008 las condiciones permisivas se van transformando en restrictivas, afectando de manera gradual pero persistente a la acción externa

producción de la aeronave KC-390 de acuerdo con los más altos estándares de calidad. Finalmente de los 29 acuerdos bilaterales firmados desde 2003 con países de la región, 10 de ellos se suscribieron con posterioridad a 2011. 
del país. En ese marco, se fue generando un proceso caracterizado por: la contracción del comercio mundial, un mayor proteccionismo, un incremento de las asimetrías con China, una intensificación de la integración vertical de la economía mundial, el abandono del multilateralismo comercial y el lanzamiento de esquemas megarregionales y la disminución de los precios de los productos primarios exportados por nuestro país. Consecuentemente, los principios de multipolaridad, reciprocidad y pluritematismo ya no podían ser alcanzados.

El impacto de los condicionantes externos sobre cuestiones estratégico-militar fue abordado a través de la variable "seguridad hemisférica", partiendo de la base que la misma permaneció como una influencia central, pero con variaciones en su intensidad lo que genera que la identificación de períodos o etapas sea menos evidente en términos comparativos con los otros condicionantes analizados. Para el tratamiento de este punto tomamos como indicadores: la aceleración del proceso de erosión de la arquitectura de seguridad interamericana; el deterioro de la imagen de Estados Unidos y la consolidación de un escenario intrarregional de paz interestatal. Estos indicadores, sumados al contexto de "giro a la izquierda" en la primera década del siglo XXI, favorecieron la sub-regionalización del diálogo y la cooperación sobre cuestiones estratégico-militares y permitieron que los gobiernos kirchneristas plantearan una política de Defensa basada en un modelo defensivo, autónomo e internacionalmente cooperativo, que tuvo como área prioritaria para su proyección externa a la región, ocupando Sudamérica el primer lugar mientras que el resto de Latinoamérica fue considerada el segundo círculo de interés estratégico. Sin embargo, algunos de los indicadores mencionados fueron incrementando su intensidad y, de esa manera, relativizaron el escenario permisivo para la política de Defensa argentina y sus manifestaciones externas vía la conexión con la PEA. Así, la voluntad de liderazgo de Washington en las cuestiones de seguridad y defensa a nivel hemisférico a partir de la segunda administración Obama, como el estancamiento de los logros en el ámbito de la defensa regional, especialmente en el CSD, son una muestra del retorno de un escenario más restrictivo que se fue haciendo más evidente de manera paralela a las limitaciones económicas que, claramente, afectaron los planes en otros ámbitos de las políticas públicas.

Los hechos y su temporalidad muestran que los tres condicionantes externos analizados transitaron desde la permisibilidad a la restricción durante las gestiones del kirchnerismo y, además, que dicha restricción fue de mayor envergadura durante el segundo mandato de Cristina Fernández.

El escenario externo tuvo, entonces, un impacto significativo sobre la PEA. En primer lugar, los condicionantes internacionales vinculados al aumento y caída de los precios de los commodities afectaron también a varios países de la región y, consecuentemente, la complejización de la situación económica también limitó las alternativas de crecimiento sudamericano alterando el contexto privilegiado por el gobierno argentino.

Por otra parte, las limitaciones de la globalización financiera y su impacto sobre las negociaciones con los fondos buitres, quienes contaron con un dictamen favorable de la justicia estadounidense, profundizaron las tensiones entre Buenos Aires y Washington y, simultáneamente, ampliaron las relaciones con China sumando la dimensión financiera a la agenda bilateral -hasta entonces había tenido prioritariamente componentes comerciales y de inversión-, en tanto también ensancharon los lazos con Rusia si comparamos su peso entre los gobiernos de Néstor y Cristina Kirchner.

Si volvemos a la conceptualización de Jaguaribe (1969) citada en la Introducción, la permisibilidad internacional habilitó condiciones de flexibilidad para que Argentina emprendiera una estrategia externa autonomizante durante buena parte de la gestión kirchnerista. Sin embargo, esa situación fue virando hacia la rigidez, motivo por el cual desde ese momento histórico el grado de condicionamientos específicos del sistema internacional fue negativo. En este marco un dato llama la atención: sin bien las posibilidades de una PE autonómica se acotaron severamente Cristina Fernández, a diferencia de otros presidentes latinoamericanos coetáneos, no declinó ni a nivel del discurso ni al nivel de las acciones en la búsqueda de esa autonomía. La evaluación sobre la conveniencia y los logros de esa decisión constituyen, aún hoy, un tema de debate. 


\section{Bibliografía}

ACTIS, E. y CREUS, N. (2015). Argentina vs los fondos buitres. El rol de Estados Unidos y la tesis de la disciplina financiera, Anuario 2015 en Relaciones Internacionales, Instituto de Relaciones Internacionales, Universidad Nacional de La Plata. Disponible en http://www.iri.edu.ar/publicaciones_iri/anuario/anuario_2015/Amnor/Actis\%20y\%20Creus.pdf

ALLISON, G. (1975). La esencia de la decisión, GEL, Buenos Aires.

BALDWIN, R.; EVENETT, S. (ed). (2009). The collapse of global trade, murky protectionism and crisis: recommendation for the G20; Londres; Centre for Economic Policy Research.

BRESSER-PEREIRA, L. C. (2010). Globalización y competencia: apuntes para una macroeconomía estructuralista del desarrollo, Bs.As., Siglo Veintiuno Editora.

BUSSO, A. (2005). La problemática de la seguridad a nivel mundial y regional. Incidencias en la PE y de Defensa de la República Argentina, en Desarrollo y Región Anuario 2004.

BUSSO, A. (2010). Política exterior y relaciones bilaterales con Estados Unidos durante el gobierno de Cristina: tensiones entre los objetivos de la campaña electoral y el renacer de los condicionantes internos, en la edición preparada por el Centro de Estudios de Relaciones Internacionales de Rosario La política exterior de Cristina Fernández. Apreciaciones promediando su mandato, UNR Editora, págs. 269-320.

BUSSO, A. (2014). Cristina y Obama: el discurrir inestable de las relaciones bilaterales y la perdurabilidad del patrón crisis-intento de recomposición, en BOLOGNA, A. B. (comp.), La Política Exterior de Cristina Fernández de Kirchner, Tomo VI, UNR Editora, Rosario, pp. 49-78.

BUSSO, A. (2016). Neoliberal-crisis, social-demands and foreign policy in Kirchnerist Argentina, en Contexto Internacional, PUC-Rio, Brasil; Special Issue on Foreign Policy and Social Demands in Latin America, $38 \quad$ (1). Disponible en: $\underline{\text { http://contextointernacional.iri.puc- }}$ rio.br/cgi/cgilua.exe/sys/start.htm?infoid=717\&sid=124

BUSSO, A. y PIGNATTA, M.E. (2006). Las relaciones Argentina - Estados Unidos después de la renegociación de la deuda. Continuidades estructurales, gestos reactivos y cuestiones irresueltas, en Anuario 2006, IRI, La Plata, Argentina, Facultad de Ciencias Jurídicas y Sociales de la Universidad Nacional de La Plata, pp $1-83 . \quad$ Disponible en: http://www.iri.edu.ar/publicaciones_iri/anuario/CD\%20Anuario\%202006/Amnor/presentacion\%20americ a\%20del\%20norte.pdf

BUSSO, A.; CEPPI, N.; FABANI, O.; NOVELLO, M; MARINI, G.; PAREDES RODRÍGUEZ, R. Y PIGNATTA, M. (2016). Inserción internacional y modelo de desarrollo en los noventa. Impactos sobre la política exterior de Menem y De la Rúa, en BUSSO, A. (coord.) Modelos de desarrollo e inserción internacional. Aportes para el análisis de la política exterior argentina desde la redemocratización (1983-2011), UNR Editora.

BUZAN, B. y WAEVER, O. (2003). Regions and Powers: The Security of International Security, Cambridge University Press, Cambridge.

CAPUTO, D. (2015). El péndulo austral: la Argentina entre el populismo y el establishment, Buenos Aires, Capital Intelectual.

CEPAL (2012). La República Popular China y América Latina y el Caribe. Diálogo y cooperación ante los nuevos desafios de la economía global, Santiago de Chile. Disponible en: http://www.cepal.org/publicaciones/xml/1/47221/ChinayALCesp.pdf. Consulta: 20 de marzo de 2013.

CEPAL (2015). América Latina y el Caribe y China hacia una nueva era de cooperación económica, Santiago de Chile. Disponible en: http://repositorio.cepal.org/bitstream/handle/11362/38196/S1500389_es.pdf. Consulta: 4 de junio de 2015.

CREUS, N. (2015). El peso de las imágenes waltzianas en la relación de Argentina con el Sistema Financiero Internacional, Análisis Político, (84), Bogotá, p. 155-166.

DAMILL, M; FRENKEL, R. (2015). La economía argentina bajo los Kirchner: una historia de dos lustros en PERUZZOTTI, E. y GERVASONI, C (eds.), ¿Década ganada? Evaluando el legado del kirchnerismo; Buenos Aires; Editorial Debate.

DECRETO 1691/2006 (2006). Directiva sobre Organización y Funcionamiento de las FFAA.

DECRETO 1714/2009 (2009). Directiva de Política de Defensa Nacional. 
EATWELL, J. y TAYLOR, L. (2005). Finanzas globales en riego: un análisis a favor de la regulación internacional, Bs. As, Siglo Veintiuno Editora.

El gobierno privilegia la industria frente al agro en la OMC, edición impresa La Nación, Buenos Aires, 13 de junio de 2007. Disponible en: http://www.lanacion.com.ar/916948-el-gobierno-privilegia-a-laindustria-frente-al-agro-en-la-omc Consulta: 16 de marzo de 2017.

El peso de China en la balanza comercial argentina tocó su máximo histórico en 2014, Diario Cronista.com, $1^{\text {o }}$ de febrero de 2015, Buenos Aires [en línea]. Disponible en: http://www.cronista.com/economiapolitica/El-peso-de-China-en-la-balanza-comercial-argentina-toco-unmaximo-historico-en-2014-20150201-0009.html Consulta: 16 de marzo de 2017.

El recuerdo de Taiana a la gestión de Kirchner en UNASUR, Infonews, 4 de mayo de 2015, Buenos Aires. Disponible en: http://www.infonews.com/nota/198021/el-recuerdo-de-taiana-a-la-gestion-dekirchner-en-unasur Consulta: 16 de marzo de 2017.

FERNANDEZ ALONSO, J. (2006). La reinserción financiera como eje rector de la agenda externa argentina post-default, en BOLOGNA B. A., La Política Exterior Argentina (2003-2005), Edición preparada por el Centro de Estudios en Relaciones Internacionales (CERIR), UNR Editora, Rosario.

FERNÁNDEZ DE KIRCHNER, C. (2010); Discurso ante Asamblea Legislativa en ocasión de Inauguración del $128^{\circ}$ período de sesiones del Congreso de la Nación, $1^{\circ}$ de marzo de 2010.

FERRER, A. (1996). Historia de la Globalización: orígenes del orden económico mundial, Vol. 1, Bs. As, Fondo de Cultura Económica.

FFRENCH-DAVIS, R. (2016). Chile y la financiación innovadora para el desarrollo: una experiencia para hacer globalización inclusiva, Estudios Internacionales, (183), Universidad de Chile, p. 67-92.

FONTANA, A. (1996). Seguridad cooperativa: tendencias globales y el continente americano, en documento de trabajo ${ }^{\circ} 16$ del Instituto del Servicio Exterior de la Nación.

FRENKEL, R. (2003). Globalización y crisis financieras en América Latina, Revista de Economía Política, 23 (3), pp. 94-111.

JAGUARIBE, H. (1969). Dependencia y autonomía en América Latina, en JAGUARIBE, H. (Et. Al.) La dependencia político-económica de América Latina, Siglo XXI, México, 1-85.

LAVAGNA, R. (2005). Política, economía y deuda, en BIELSA, R.; LAVAGNA R. y ROSATTI, H. (Comp.), Estado y Globalización, Santa Fe, Argentina, Rubinzal-Culzoni Editores, 64-101.

LASAGNA, M. (1996). Cambio institucional y política exterior: un modelo explicativo, en Revista CIDOB d'Afers Internacionals, (32), Barcelona. Disponible en: www.cidob.org/es/content/download/6894/68970/file/32lasagna.pdf

Los enigmas del pago al Club de París, Página 12, 5 de septiembre de 2008, Buenos Aires. Disponible en: https://www.pagina12.com.ar/diario/economia/2-111035-2008-09-05.html Consulta: 16 de marzo de 2017.

KULFAS, M. (2014). La economía argentina, entre la "década ganada" y los "fondos buitre", Nueva Sociedad, (254), p. 4-16.

MECON (2004). Lineamientos de la política comercial externa de Argentina. Disponible en http://www.sice.oas.org/ctyindex/ARG/PolEco s.pdf. Consulta: 26 de diciembre de 2016.

MIGUEZ, M.C. (2016). La política exterior argentina y su vinculación con los condicionantes internos en el siglo XXI, en Revista Relaciones Internacionales, (89.2), Costa Rica, Julio-diciembre, págs. 125-142.

MILITARY CONSTRUCTION PROGRAM (2009). Fiscal Year 2010 Budget Estimates of Department of the Air Force, Disponible en http://www.centrodealerta.org/documentos_desclasificados/original_in_english_air_for.pdf Consulta: 15 de febrero de 2017.

MINISTERIO DE DEFENSA (2015). Libro Blanco de la Defensa Nacional, Buenos Aires.

MIRANDA, R. (2012). Des-inserción argentina. Las políticas exteriores de Menem y Kirchner, en Enfoques: Ciencia Política y Administración Pública, X (17). 
MIRANDA, R. (2014). Vinculación de cuestiones. La relación de Argentina con Estados Unidos durante su des-endeudamiento, en Revista De La Facultad De Ciencias Económicas - UNNE, (12), p.18-41.

MORGEnTHAU, H. J. (1948). Politics Among Nations: The Struggle for Power and Peace, A. A. Knopf.

NEMIÑA, P. (2013). Dominación, confrontación y acuerdo. La intervención del FMI en la crisis argentina durante 2002, en Conjuntura Austral, 4 (19), pp. 11-34.

NUDELSMAN, S. (2013). Implicaciones de la crisis financiera y económica global en América Latina, en Problemas del desarrollo, 44 (17), p. 125-146.

OMC (2010). Informe sobre el comercio mundial 2010; Ginebra, WTO Press.

OMC (2012). Informe sobre el comercio mundial 2012; Ginebra, WTO Press.

OMC (2015). Informe sobre el comercio mundial 2015; Ginebra, WTO Press.

PAZ, G. S. (2013). Argentina and Asia: China's Reemergence, Argentina's Recovery en ARNSON, C; HEINE, J.; ZAINO, C.; Reaching Across the Pacific: Latin America and Asia in the New Century; Woodrow Wilson International Center, Washington.

PETRELLA, F. (2011). Argentina: gobernanza global y su participación en el G20, en Diálogo Político, 28 (4), 75-90.

PUTNAM, R. (1988). Diplomacy and Domestic Politics: The Logic of Two-Level Games, en International Organization, 42, Cambridge University Press, Cambridge, pp. 427-460.

ROLDAN PEREZ, A.; CASTRO LARA, A.; PEREZ RESTREPO, C.; (2016). La presencia de China en América Lantina. Comercio, Inversión y Cooperación económica; Colombia; Fundación Konrad Adenauer.

ROSENAU, J. (1967) (Ed.) Domestic Sources of Foreign Policy, The Free Press-Collier-Macmillan Limited, New York-Londres.

RUSSELL, R. (1991). Variables Internas y Política Exterior, ponencia presentada en el taller de trabajo sobre "Cuestiones Técnicas y Metodológicas para el Estudio de la Política Exterior", organizado por FLACSO - área Relaciones Internacionales -, Buenos Aires 18 y 19 de abril.

RUSSELL, R. y TOKATLIAN, J.G. (2013). América Latina y su gran estrategia: entre la aquiescencia y la autonomía, Revista Cidob d'Afers Internacionals, (104), pp. 157-180.

RUSSELL, R. y TOKATLIÁN, J.G. (2015). La Política Exterior del Kirchnerismo, en GERVASONI, C. y PERUZZOTTI, E. (compiladores), ¿Década Ganada? Evaluando el legado del Kirchnerismo, Debate, Universidad Torcuato Di Tela, Buenos Aires, pp. 235-269.

SIMONOFF, A. (2010). La Argentina y el mundo frente al bicentenario de la Revolución de mayo; La Plata; Universidad Nacional de La Plata.

SOARES DE LIMA, M.R. (1994). Ejes analíticos y conflicto de paradigmas en la política exterior brasileña, en América Latina Internacional, 1 (2), otoño-invierno, Buenos Aires.

VADELL, J., ARAÚJO, R. y CERQUEIRA, G. (2016). China y la nueva ofensiva financiera en América Latina: los acuerdos con Argentina, en LECHINI, G. y GIACCAGLIA, C. (Eds.), Poderes emergentes y Cooperación Sur-Sur: perspectivas desde el Sur Global, Rosario, UNR Editora.

VILLAMAR, Z. (2016). BRIC: 15 años del acrónimo del siglo XXI; en Revista Nueva Sociedad, (266); Noviembre-Diciembre; pp. 4-15. Disponible en http://nuso.org/articulo/bric-15-anos-del-acronimo-delsiglo-xxi/ Consulta: 26 de diciembre de 2016.

ZELICOVICH, J. (2015). ¿Pueden los países en desarrollo ejercer influencia en las negociaciones multilaterales? Consideraciones en torno al caso argentino en la Ronda Doha (2001-2011), en Temas y Debates, (29), pp. 79-100. 